\title{
Microstructural and Mechanical Characterization of Shielded Metal Arc Welded Dual Phase Steel Joints
}

\author{
Walid Laroui $^{1}$, Redouane Chegroune ${ }^{1 *}$, Şükrü Talaş ${ }^{2}$, Mourad Keddam $^{1}$, Riad Badji ${ }^{3}$ \\ ${ }^{1}$ Laboratory of Materials Technology, Faculty of Mechanical and Process Engineering, University of Sciences and Technology \\ Houari Boumediene, Bab-Ezzouar, Algiers 16111, Algeria \\ ${ }^{2}$ Faculty of Technology, Afyon Kocatepe University, ANS Campus, Afyonkarahisar 03200, Turkey \\ ${ }^{3}$ Research Center in Industrial Technologies CRTI, PO Box 64, Cheraga 16002, Algeria
}

Corresponding Author Email: rchegroune@usthb.dz

https://doi.org/10.18280/acsm.440602

Received: 6 August 2020

Accepted: 24 November 2020

\section{Keywords:}

dual-phase steel, fractography, heat affected zone, heat treatment, welding

\begin{abstract}
Dual Phase steels are widely used in industry for various reasons for their improved mechanical properties owing to their ferrite and martensite contents in microstructure and good formability at industrial scale to achieve final shape with good ductility. In this study, shielded metal arc welding experiments were performed in order to evaluate the metallurgically and mechanically the properties of Dual Phase steels obtained from plain carbon steel AISI 1010 by water quenching at intercritical temperatures. Martensite volume fraction (MVF) was related to the intercritical quenching temperature which defines the mechanical properties of Dual Phase steel. All the welding parameters were kept constant in order to get a value of heat input equals $1.37 \mathrm{KJ} / \mathrm{mm}$ for all weldments Martensite was found to be predominated in the fusion zone and its hardness was the highest compared to base metal (BM) and heat affected zone (HAZ). The extent of ductile zone was found to be dependent on the MVF and reached over $1.2 \mathrm{~mm}$ wide. Tensile properties of weldments were deteriorated by $35 \%$ in ultimate tensile strength (UTS) and by $15 \%$ in elongation. The failure of all the welded joints was occurred in the SC zone, with the fractured surfaces of a dimple feature.
\end{abstract}

\section{INTRODUCTION}

Throughout the last decade has witnessed a significant increase in Advanced High-Strength Steels (AHSS) over typical micro alloyed steels in the automotive sector. The Dual Phase steels, characterized by dual phase microstructure, are known for their large capability of deformation and a good ductility with a low yield strength [1-3]. These properties are related to the microstructure containing ferrite plus martensite phases and hence Dual Phase steel. Different heat treatments were employed to obtain this microstructure. For instance, during the intercritical quench heat treatment, the austenite phase transforms into martensite phase after a rapid cooling rate [4]. The mechanical properties of the Dual Phase steel are basically affected by the volume fraction of martensite. During the welding operation, the Dual Phase steels were characterized by a softness of the sub-critical region of the HAZ. It is due to the occurrence of tempered martensite in the base metal and thereby decreasing the local hardness value [520]. The tempered martensite is resulting from an isothermal heat treatment through a series of steps up to $\mathrm{AC} 1$ temperature. This heat treatment is necessary to get an acceptable strength for Dual Phase steels. During the tempering stage, there are different phenomena which could appear: the decomposition of retained austenite, the transformation of $\epsilon$-iron carbide into cementite or alloyed carbides, the coarsening of cementite and the recovery of martensite [5].

In recent years, a great number of researches works on the welding of dual phase was available in the literature [5-21].
The main processes used to weld dual phase steels are the resistance spot welding (RSW) and laser welding (LW).

The RSW process is very helpful to weld both dissimilar DP steels and thicknesses [6]. However, Aslanlar et al. [11] reported that the weld current and time affected the mechanical properties of resistance spot welded dissimilar Dual Phase steels. The soft zone in HAZ produced in the heat affected zone by RSW process on dual phase steels has already been studied by Hernandez et al. [5, 7-10]. Additionally, the softening phenomenon was also observed in laser welding process [12-20]. Previous studies on the weldability of Dual Phase steels [5-20] showed that the softening of HAZ depended on the two key parameters (the volume fraction of martensite and the heat input value. This phenomenon leads to a decrease in the formability and most tensile tests failed in this zone due to lower hardness in comparison to that of base metal.

Shielded metal arc welding (SMAW) is known as the simplest of the all arc welding processes. The equipment is often small in size and is movable and its cost is very low. This process finds many applications because of the availability of a wide variety of electrodes which makes it possible to weld various metals and their alloys. Therefore, this process is widely used in many industrial applications. A certain level of operational skills is needed in performing the SMAW process in order to obtain an acceptable quality of weldment.

Furthermore, input process parameters such as current, voltage, arc gap, welding speed, electrode orientation play a vital role in the quality of the weldment. Therefore, Taguchi 
method was used to optimize the welding parameter [21-23] Since dual-phase steels are widely required in automobile manufacturing, the research works focused on automotive welding processes (RSW, LW) and Shielded Metal Arc Welded Dual Phase steel joints has not been undertaken. The AISI 1010 steel is widely used in many industrial sectors due to its low cost and formability. It is a good candidate for welding operations because of its low content of carbon.

The objective of the current study is to characterize metallurgically and mechanically the welded joints of heat treated AISI 1010 steel by using the Shielded Metal Arc Welding for the specified condition.

\section{MATERIAL AND EXPERIMENTAL PROCDURE}

\subsection{Material}

In this study, the material used for the welding operations was the dual phase AISI 1010 steel. This steel was supplied as plates by National Company of Industrial Vehicles (SNIVI), Algeria, with the chemical composition and the critical temperatures of phase transformation presented in Table 1 . Five samples of AISI 1010 steel with different martensite volume fractions were used for welding. Different volume fractions of martensite were obtained by performing the intercritical heat treatments. In order to obtain a mixture of (ferrite + martensite) in the microstructure, this plain carbon steel was heat-treated in (ferrite + austenite) two-phase region at different temperatures: $750^{\circ} \mathrm{C}, 770^{\circ} \mathrm{C}, 790^{\circ} \mathrm{C}, 810^{\circ} \mathrm{C}$ and $840^{\circ} \mathrm{C}$ for $30 \mathrm{~min}$, followed by water-quenching.

Table 1. Chemical composition of AISI 1010 steel with the critical temperatures of phase transformation. $\left(\mathrm{Ac}_{1}=738^{\circ} \mathrm{C}\right.$ and $\mathrm{Ac}_{3}=850^{\circ} \mathrm{C}$ )

\begin{tabular}{cc}
\hline Elements (wt \%) & AISI1010 \\
\hline $\mathrm{C}$ & 0.11 \\
$\mathrm{Si}$ & 0.234 \\
$\mathrm{Mn}$ & 0.474 \\
$\mathrm{P}$ & 0.002 \\
$\mathrm{~S}$ & 0.037 \\
\hline
\end{tabular}

\subsection{SMA welding}

The assemblies to be welded from S-27 to S-70 (Table 3) had a single- $\mathrm{V}$ bevel profile, with an angle of $60^{\circ}$ and ratio of $1 / 3(2 \mathrm{~mm})$ and 2/3 (4 mm) in the formation of the bevel, root opening of $2 \mathrm{~mm}$ tolerance in total. The chemical composition of the used coated electrode E7016 is listed in Table 2. The welding operation was carried out in flat position (1G).

Table 2. Chemical composition of coated electrode E7016

\begin{tabular}{cc}
\hline Elements (wt\%) & E7016 \\
\hline $\mathrm{C}$ & 0.09 \\
$\mathrm{Si}$ & 0.50 \\
$\mathrm{Mn}$ & 0.80 \\
$\mathrm{P}$ & 0.011 \\
$\mathrm{~S}$ & 0.005 \\
\hline
\end{tabular}

Figure 1 shows the geometry of the joint used. The welding parameters selected for this study are listed in Table 3.

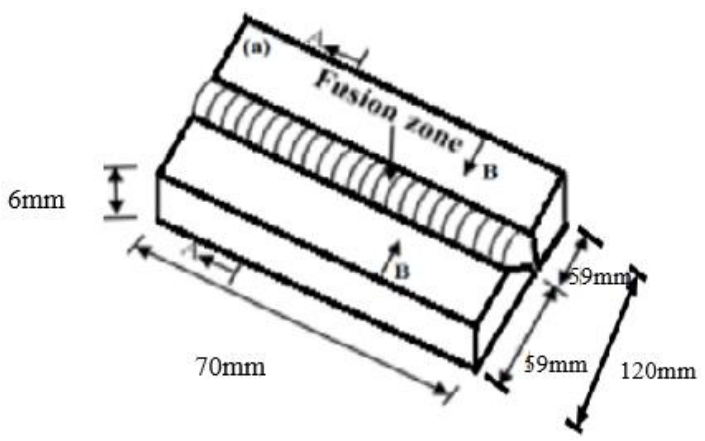

(a)

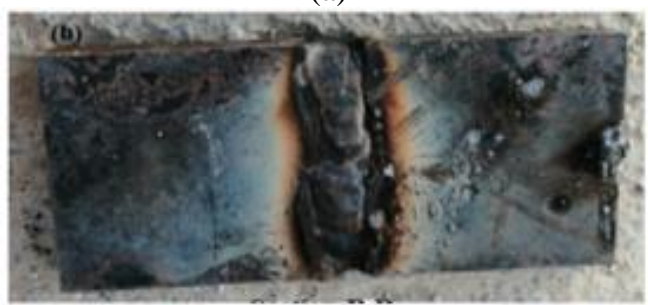

Section B-B

(b)

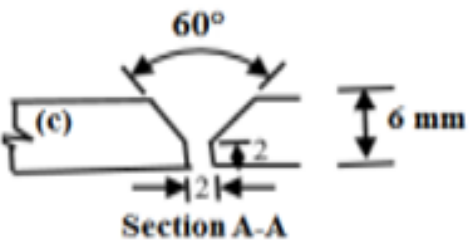

(c)

Figure 1. Geometry of the joint. (a) Schematic representation (b) weldment of S-27 (sectional view B-B) (c) Section A-A

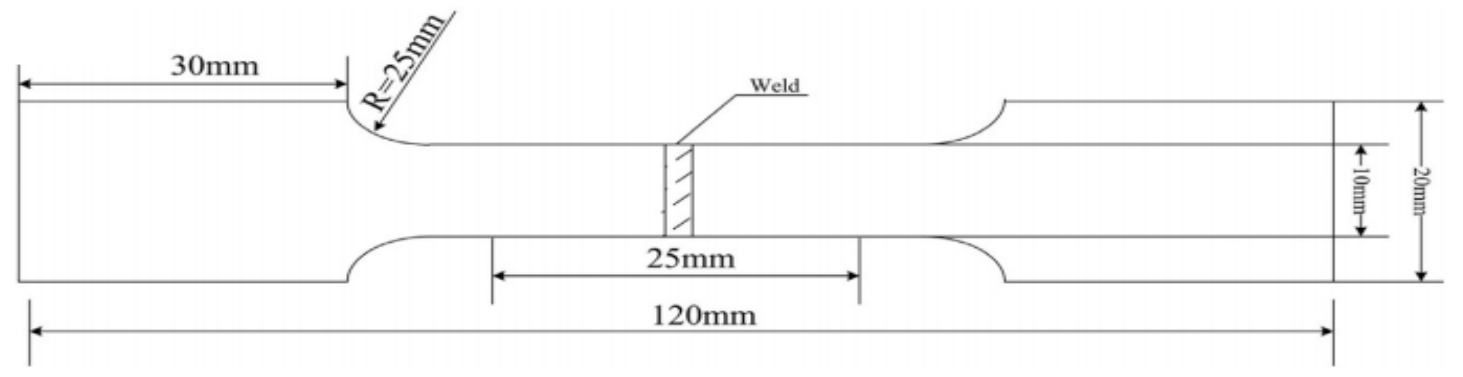

Figure 2. Geometry and dimensions of the tensile test specimens

Table 3. Selected SMAW welding parameters

\begin{tabular}{cccccc}
\hline Samples & Filler material diameter/mm & Current $(\mathbf{A})$ & Voltage $(\mathbf{V})$ & Welding speed $(\mathbf{m m} / \mathbf{m i n})$ & Heat input (kJ/mm) \\
\hline S-27 to S-70 & 3.2 & 115 & 20 & 100 & 1.38 \\
\hline
\end{tabular}




\subsection{Mechanical testing}

Figure 2 shows the geometry and shape of tensile test specimens according to GB/T2651-2008. The welded specimens were machined in the perpendicular direction of welding. Tensile tests were carried out at ambient temperature with a velocity of $2 \mathrm{~mm} / \mathrm{min}$ in all conditions. The values of ultimate tensile strength (UTS) and elongation were deducted from the plots.

The Vickers hardness test was conducted on the etched specimens under a load $200 \mathrm{~g}$ with a dwell time of $10 \mathrm{~s}$. The hardness tester is a VH3300 Automatic Hardness tester. The test areas cover the base metal and weld zones.

\subsection{Microstructural observation and analysis of fracture}

For microscopic examinations, the welded samples were prepared by using the wire-electrode cutting. Afterwards, they were subjected to the standard metallographic procedure and etched with $4 \%$ Nital solution. The microstructures of base metal and weld zone were examined with an optical microscope (Eclipse MA100) and Scanning electron microscope (JSM6360 LV). Particularly, the fractured surfaces of specimens subjected to the tensile test were observed with scanning electron microscope to define the failure mechanism.

\section{RESULTS AND DISCUSSIONS}

\subsection{Microstructures of base metals}

Figure 3 shows OM and SEM images of the microstructure of water-quenched AISI 1010 after austenitizing at $750^{\circ} \mathrm{C}$ during $30 \mathrm{~min}$. The obtained microstructure revealed the presence of two different regions. The light region is attributed to ferrite while the brown one represents the martensite in Figure 3a. For the SEM observation, the gray area is belonging to ferrite and the area with relief is the martensite (Figure 3b).
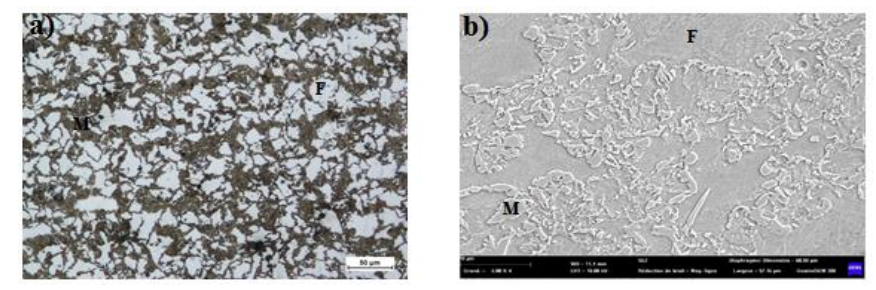

Figure 3. Microscopic observations of microstructure of water-quenched AISI 1010 steel, austenitized at $750^{\circ} \mathrm{C}$ for 30 min a) OM microstructure and b) SEM microstructure. The symbols $\mathrm{M}$ and $\mathrm{F}$ denote respectively martensite and ferrite

The martensite volume fractions were carried out by quantitative metallography according to ASTM E562 and with the help of ImageJ software on the microstructures of heat treated AISI 1010 steel for different austenitizing temperatures. The results of measured martensite volume fractions are displayed in Table 4.

\subsection{Weld geometry profile}

Figure 4 shows a schematic representation of the crosssection of S-27 welded joint where five different zones could be noticed. The location ' $a$ ' in this figure corresponds to the sub-critical heated affected zone (S-C HAZ) with the peak temperature less than Ac1. The location ' $b$ ' represents the inter-critical heated affected zone (I-C HAZ) with the peak temperature ranging from Ac1 to Ac3. The location ' $c$ ' has a fine grained (F-G) microstructure, the location ' $d$ ' is the zone with a coarse - grained (C-G) microstructure and finally the diffusion zone is designated by the location ' $e$ '.

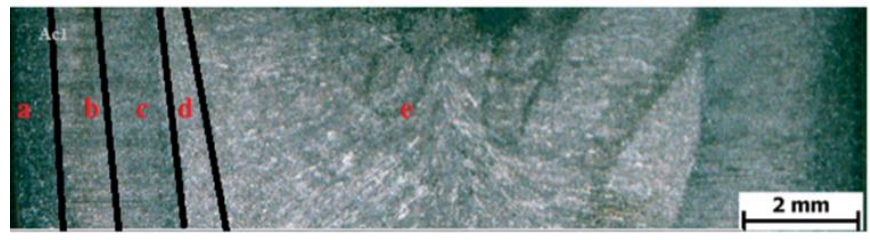

Figure 4. Schematic representation of the cross section of S27 welded joint

It was reported that the value of heat input impacted on the mechanical properties of the welded joints $[4,6-16,18,20]$. Therefore, in this work, the welding speed, voltage and current were the same in all welds to keep the heat input constant. In Figure $1 \mathrm{~b}$ is shown a non-concave weld bead obtained after welding the S-27 sample.

The cross section of the weldment for $\mathrm{S}-27$ is shown in Figure 4. A total penetration can be obtained for all weldments with energy input of $1.38 \mathrm{~kJ} / \mathrm{mm}$. When the martensite volume fraction of $\mathrm{BM}$ ranging from $27 \%$ to $70 \%$, the width of softening region increases from 0.90 to $1.45 \mathrm{~mm}$, respectively. In Table 5 are gathered the values of weld width and softening zone width depending on the values of martensite volume fractions.

Table 4. Martensite volume fractions measured for different conditions on heat treated AISI 1010 steel

\begin{tabular}{lc}
\hline Heat treatments & $\begin{array}{c}\text { Martensite volume } \\
\text { fraction (\%) }\end{array}$ \\
\hline S-27: Austenitized at $750^{\circ} \mathrm{C}$ for $30 \mathrm{~min}$ & 27 \\
S-31: Austenitized at $770^{\circ} \mathrm{C}$ for $30 \mathrm{~min}$ & 31 \\
S-40: Austenitized at $790^{\circ} \mathrm{C}$ for $30 \mathrm{~min}$ & 40 \\
S-52: Austenitized at $810^{\circ} \mathrm{C}$ for $30 \mathrm{~min}$ & 52 \\
S-70: Austenitized at $840^{\circ} \mathrm{C}$ for $30 \mathrm{~min}$ & 70 \\
\hline
\end{tabular}

Table 5. Weld width and softening zone width for different values of martensite volume fractions

\begin{tabular}{ccc}
\hline Sample & Weld width $(\mathbf{m m})$ & sub-critical HAZ width $(\mathbf{m m})$ \\
\hline S-27 & 5.1 & 0.90 \\
S-31 & 5.3 & 0.95 \\
S-40 & 5.1 & 1 \\
S-52 & 5 & 1.2 \\
S-70 & 5.2 & 1.45 \\
\hline
\end{tabular}

\subsection{Tensile test results and analysis of fractured surface}

The tensile results of base metals and welded specimens are shown in Figure 5. The non-isothermal heat treatment of SMAW process decreases the ultimate tensile strength (UTS) of welded metals by approximately $35 \%$ as shown in Figure 5a. The UTS of base metal (BM) was improved by $2.1 \%$, when martensite volume fraction (MVF) reached 70\%. Meanwhile, UTS of welded metal (WM) was improved by $1.2 \%$. 
The elongation of welded joints was also influenced by SMAW process which was decreased by approximately $15 \%$. As the martensite volume fraction (MVF) increases, the elongation of base metals (BM) and welded joint (WJ) decrease as illustrated in Figure $5 b$.
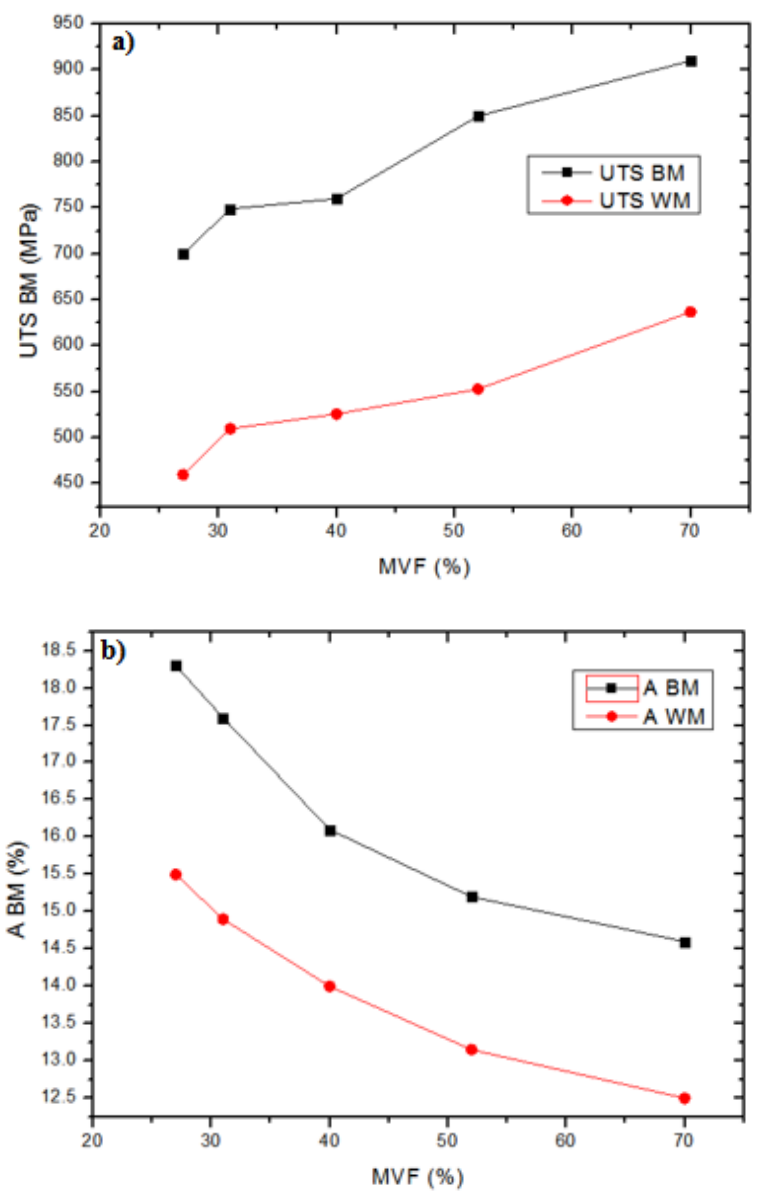

Figure 5. Tensile test curves of the BM and WM depending on the value of MVF, (a) UTS, and (b) elongation

The failure occurred at the sub-critical heated affected zone (S-CHAZ) for all welded joints where the microstructures consist of ferrite and tempered martensite; consequently, the fracture surface shows dimpled cuplike fracture according to Figure 6.

The microstructures of tempered martensite were the same, containing a ferritic matrix with precipitation of carbides. The response to the plastic deformation during the tensile tests of such microstructures was the same giving rise to the ductile fractured surfaces with the presence of dimples. When heat input was constant, the MVF of Dual Phase steels do not contribute to the change in the fracture type.

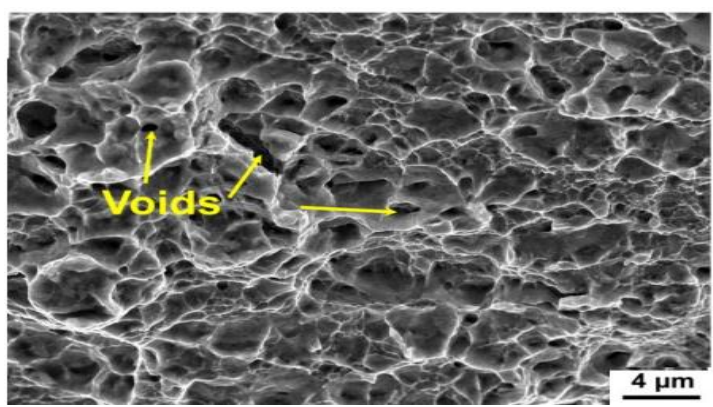

Figure 6. Typical SEM micrograph of the fracture of S-40 welded joint subjected to tensile test.

\subsection{Vickers hardness measurements}

Figure 7 gives a microhardness profile along the crosssection of S-40 welded joints. It is noticed that the microhardness value depends on the location of welded zone. The measured microhardness value in the fusion zone was the highest and attained $320 \mathrm{HV} 0.2$. The effect of hardening was visible in the region near the fusion zone in the vicinity of HAZ zone with a higher value of microhardness compared to the base metal. The microhardness of this region located at 1.8 $\mathrm{mm}$ from the fusion line, was between 225 and 300 HV0.2. It is seen that the region situated near the base metal (in the outer HAZ) had a lower microhardness in comparison with the base metal. This region is referred to as the softening zone is characterized by a lower value of microhardness ranging from 171 to $190 \mathrm{HV} 0.2$. It was reported that the occurrence of this softening zone exerted a negative effect on the mechanical characteristics of welded joints [5, 7-9, 12-20]. Furthermore, the microhardness of the base metal remained unchanged in all tested samples. The microstructure of the base metal contained the martensite within the ferritic matrix.

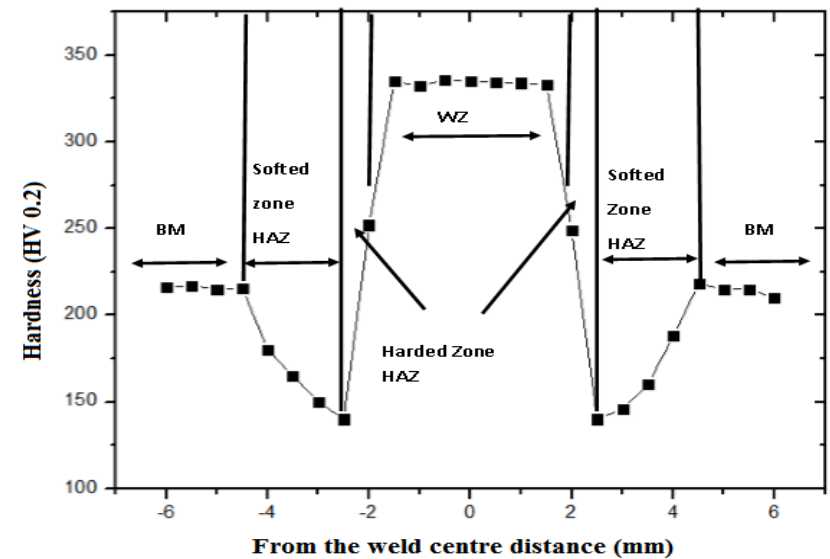

Figure 7. Typical hardness distribution of S-40 welded joint

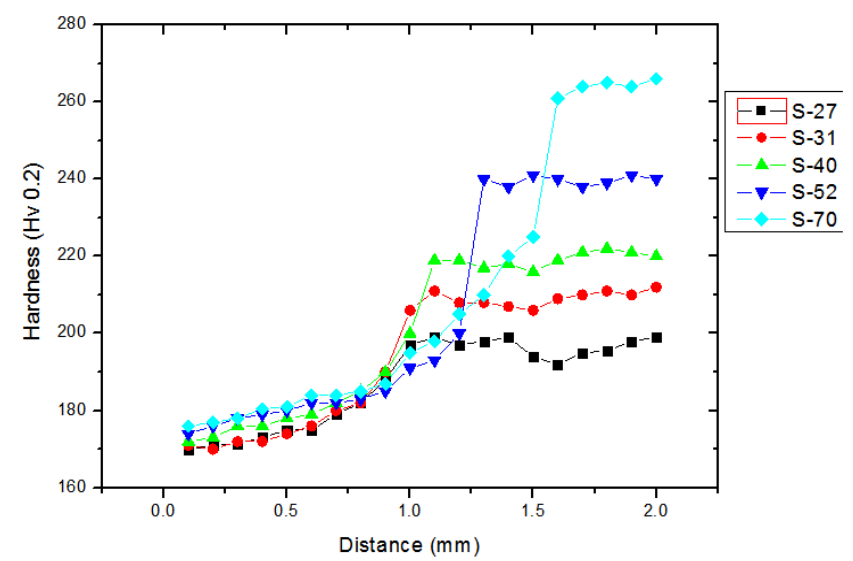

Figure 8. Microhardness profiles along the softened zones of welded joints.

Figure 8 shows the microhardness profiles along the softening zones of welded joints. In the sub-critical heated affected zone (S-C HAZ), the microhardness value increases gradually with the distance from Ac1 up to the microhardness value corresponding to that of the base metal. The minimum value of microhardness (=171 HV0.2) was reached for a distance of $0.1 \mathrm{~mm}$ from Ac1 in the direction of base metal. For a distance of $0.8 \mathrm{~mm}$, the measured value of 
microhardness reached $182 \mathrm{HV} 0.2$. while for a distance of 1.1 $\mathrm{mm}$, its value was equal to $210 \mathrm{HV} 0.2$. A rise of the martensite volume fraction (MVF) leads to the increase of the distance from Ac1 to the base metal increased. As a consequence, the width of the soft region becomes important with the increase in the martensite volume fraction. For a martensite volume fraction of $70 \%$, the measured width attained a value of 1.1 $\mathrm{mm}$.

\subsection{Microstructure}

The generated microstructure in the welded joints is determined by the thermal cycle performed. Therefore, the peak temperature decreased with the distance from the weld centerline. During the welding operation, the main parameter influencing the properties of DP steels was the heat energy input. It had a great effect on the generated microstructure $\mathrm{s}$ in the weld zone and heat affected zone (HAT) of the welded joints [16]. Therefore, many experiments were achieved in order to obtain the same heat input for all the weldments.
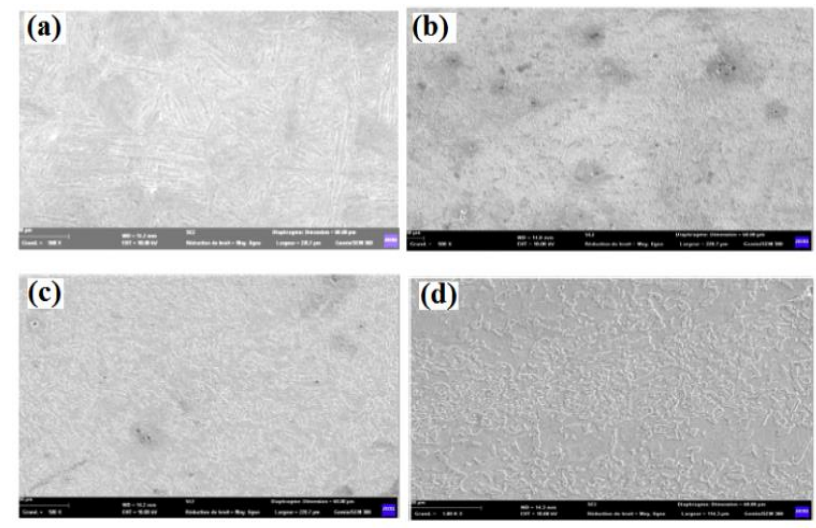

Figure 9. SEM micrographs of S-40 welded steel joints, (a) FZ, (b) CG-HAZ, (c) IC-HAZ, (d) SC-HAZ (soft zone)

Figure 9 gives the SEM micrographs of thS-40 welded steel joints in two zones (the fusion zone and heat affected zone). In Figure 9a, the peak temperature exceeds the melting point of material within the fusion zone, the resulting microstructure contained only the martensite phase.

Although base metals have different strength due to the martensite content, the microstructures of the fusion zones remained unchanged. Contrary to the previous studies that the fusion zone depends on the strength of base metals $[9,12,13]$. These results support that the fusion zones are dependent of the hardenability of base metals. The width of the fusion zones was approximately $5 \mathrm{~mm}$ due to the selected value of heat input which is constant and equal to $1.38 \mathrm{~kJ} / \mathrm{mm}$. Here we can introduce carbon equivalent formula [24] which help us to understand the hardenability of base metal.

When overheating occurs during the welding stage, the martensite phase present in the heat affected zone undergoes a phase transformation into ferrite and austenite. The grain size of heat affected zone is mainly influenced by the thermal gradient. The microstructure of this zone at room temperature contained equiaxed martensite, with a microhardness value lower than that of the weld metal. The microstructure of intercritical heat affected zone (I-C HAZ) was composed of ferrite and martensite (Figure 9c).

For peak temperature lower than Ac1, the tempered martensite undergoes a decomposition into polygonal ferrite and granular carbides (Figure 9d) with appearance of the soft zone. Similar results have also been reported in other grades of welded dual phase steels [5, 7, 13-20]. As the proportion of martensite in the base metal increases, the softening region in HAZ is enlarged.

\section{CONCLUSIONS}

In the present work, metallurgical and mechanical characterization were carried out on both dual phase base metals and dual phase SMAW joints.

The following concluding points can be drawn from the present study:

1. Dual phase steels were successfully produced from plate plan carbon steel AISI 1010 by inter-critical quenching and its mechanical properties were depended on the martensite volume fraction (MVF) of the weld metal and HAZ.

2. The martensite volume fraction on base metal increased with the intercortical-quench temperature. As the martensite volume fraction reached $70 \%$, the UTS value increased by $2.1 \%$ and the elongation slightly decreased.

3. The fusion zone was hardened as a result of a rapid cooling accompanied with the formation of martensite phase in the welding stage. The microstructures and hardness of fusion zone are not affected after welding. The microstructure of fusion zone was controlled by the heat input of SMAW process.

4. Soft zone in the SC-HAZ was characterized by the lowest hardness due to the existence of tempered martensite in the Dual Phase steels. The extent of soft zone was found to be dependent on the MVF and the width of this zone reached over $1.2 \mathrm{~mm}$ wide.

5. Tensile properties of weldments was deteriorated by $35 \%$ in UTS and by $15 \%$ in elongation. The failure of all welded joints occurred in the soft zone, and the fractured surfaces were characterized by the presence of dimples. Therefore, MVF of DP steels do not contribute to the change in the fracture type of Dual Phase welded joint.

\section{REFRENCES}

[1] Kadkhodapour, J., Schmauder, S., Raabe, D., Ziaei-Rad, S., Weber, U., Calcagnotto, M. (2011). Experimental and numerical study on geometrically necessary dislocations and non-homogeneous mechanical properties of the ferrite phase in dual phase steels. Acta Materialia, 59(11) 4387-4394. https://doi.org/10.1016/j.actamat.2011.03.062

[2] Sodjit, S., Uthaisangsuk, V. (2012). Microstructure based prediction of strain hardening behavior of dual phase steels. Materials \& Design, 41: 370-379. http://dx.doi.org/10.1016/j.matdes.2012.05.010

[3] Sarwar, M., Priestner, R. (1996). Influence of ferritemartensite microstructural morphology on tensile properties of dual-phase steel. Journal of Materials Science, 31: 2091-2095. https://doi.org/10.1007/BF00356631

[4] Advanced High Strength Steel (AHSS) Application Guidelines: 'International Iron and Steel Institute', 2009.

[5] Hernandez, B., Panda, K., Okita, Y., Zhou, Y. (2010). A study on heat affected zone softening in resistance spot welding dual phase steel by nanoindentation. Journal of 
Materials Science, 45: 1638-1647. https://doi.org/10.1007/s10853-009-4141-0

[6] Zhang, H., Qiu, X., Bai, Y., Xing, F., Yu, H., Shi, Y. (2014). Resistance spot welding macro characteristics of the dissimilar thickness dual phase steels. Materials \& Design, 63: 151-158. http://dx.doi.org/10.1016/j.matdes.2014.05.060

[7] Zhang, H., Wei, A., Qiu, X., Chen, J. (2016). Microstructure and mechanical properties of resistance spot welded dissimilar thickness DP780/DP600 dualphase steel joints. Materials \& Design, 54: 443-449. http://dx.doi.org/10.1016/j.matdes.2013.08.027

[8] Nikoosohbat, F., Kheirandish, S., Goodarzi, M., Pouranvari, M., Marashi, H. (2010). Microstructure and failure behaviour of resistance spot welded DP980 dual phase steel. Materials Science and Technology, 26(6): 738-744. https://doi.org/10.1179/174328409X414995

[9] Pouranvari, M., Marashi, H. (2010). Key factors influencing mechanical performance of dual phase steel resistance spot welds. Science and Technology of Welding and Joining, 15(2): 149-155. https://doi.org/10.1179/136217109X12590746472535

[10] Ordoñez, J.H., Ambriz, R.R., García, C., Plascencia, G., Jaramillo, D. (2019). Overloading effect on the fatigue strength in resistance spot welding joints of a DP980 steel. International Journal of Fatigue, 121: 163-171. https://doi.org/10.1016/j.ijfatigue.2018.12.026

[11] Aslanlar, Y., Özsaraç, U., Kekik, M., Barlas, Z., Aslan, H., Aslanlar, S. (2018). The effect of welding parameters on tensile-shear force of resistance spot welded dissimilar dual-phase steels. 19th International Metallurgy and Materials Congress.

[12] Li, J., Nayak, S., Biro, E., Panda, K., Goodwin, F., Zhou, Y. (2013). Effects of weld line position and geometry on the formability of laser welded high strength low alloy and dual-phase steel blanks. Materials and Design, 52: 757-766. http://dx.doi.org/10.1016/j.matdes.2013.06.021

[13] Farabi, N., Chen, L., Zhou, Y. (2012). Tensile properties and work hardening behavior of laser-welded dual-phase steel joints. Journal of Materials Engineering and Performance, 21: 222-230. https://doi.org/10.1007/s11665-011-9865-8

[14] Xia, S., Kuntz, L., Tian, L., Zhou, Y. (2008). Failure study on laser welds of dual phase steel in formability testing. Institute of Materials, Minerals and Mining, 13(5):

378-387.
https://doi.org/10.1179/174329308X299977

[15] Farabi, N., Chen, L., Zhou, Y. (2010). Fatigue properties of laser welded dual-phase steel joints. Procedia

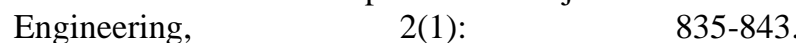
https://doi.org/10.1016/j.proeng.2010.03.090

[16] Wang, J., Yang, L., Sun, M., Liu, T., Li, H. (2016). Effect of energy input on the microstructure and properties of butt joints in DP1000 steel laser welding. Materials and Design, 90 : 642-649. http://dx.doi.org/10.1016/j.matdes.2015.11.006

[17] Saha, C., Westerbaan, D., Nayak, S., Biro, E., Gerlich, P., Zhou, Y. (2014). Microstructure-properties correlation in fiber laser welding of dual-phase and HSLA steels. Materials Science and Engineering À, 607: 445-453. http://dx.doi.org/10.1016/j.msea.2014.04.034

[18] Dong, D., Liu, Y., Yang, Y., Li, J., Ma, M., Jiang, T. (2014). Microstructure and dynamic tensile behavior of DP600 dual phase steel joint by laser welding. Materials Science and Engineering A, 594: 17-25. http://dx.doi.org/10.1016/j.msea.2013.11.047

[19] Farabi, N., Chen, L., Li, L., Zhou, Y., Dong, J. (2010). Microstructure and mechanical properties of laser welded DP600 steel joints. Materials Science and Engineering A, 527(4-5): 1215-1222. https://doi.org/10.1016/j.msea.2009.09.051

[20] Sreenivasan, N., Xia, M., Lawson, S., Zhou, Y. (2008). Effect of laser welding on formability of DP980 steel. Journal of Engineering Materials and Technology, 130(4): 1-9. https://doi.org/10.1115/1.2969246

[21] Thakur, P.P., Chapgaon, A.N. (2017). Effect of GTAWSMAW hybrid welding process parameters on hardness of weld. International Journal of Engineering Research and Technology, 10(1): 782-786.

[22] Ravikumar, S.M., Vijian, P. (2014). Optimization of weld bead geometry in shielded metal arc welding using taguchi based grey relational analysis. International Journal of Mechanical and Mechatronics Engineering, 14(4): 86-91.

[23] Mert, T., Ekinci, S. (2017). Fume formation rate analysis of shipbuilding steel with smaw using Taguchi design and ANOVA. Acta Physica Polonica A, 131(3): 495-499. https://doi.org/10.12693/APhysPolA.131.495

[24] Talas, S. (2010). The assessment of carbon equivalent formulas in predicting the properties of steel weld metals. Materials and Design, 31(5): 2649-2653. https://doi.org/10.1016/j.matdes.2009.11.066 